\title{
THE COST OF CREDIBILITY: EXPLAINING RESISTANCE TO INTERSTATE DISPUTE RESOLUTION MECHANISMS
}

\author{
ANDREW T. GUZMAN*
}

\begin{abstract}
This paper explains why the use of mandatory dispute resolution clauses is the exception rather than the rule in international agreements. On one hand, these clauses increase the sanction for violation of the agreement and thereby increase the probability that the parties will comply. On the other hand, dispute resolution clauses impose a loss on the parties when violations occur. States, therefore, must balance the credibility and compliance benefits of a mandatory dispute resolution provision against the joint costs imposed by those provisions in the event of a violation. The paper develops a series of predictive and normative results based on the trade-off. For example, dispute resolution clauses are more likely in low-stakes than high-stakes agreements, in multilateral rather than bilateral agreements, and when tribunals are more accurate. The paper also offers support for the view that money damages (or other zero-sum transfers) should be encouraged in international dispute resolution.
\end{abstract}

\section{INTRODUCTION}

$\mathbf{W}_{\mathrm{r}}$ ITHIN domestic legal systems, courts stand ready to resolve legal disputes. In the international realm, there have been attempts to create analogous institutions to resolve disputes between states. These attempts include the establishment of the International Court of Justice (ICJ), the dispute resolution procedures of the World Trade Organization (WTO), the United Nations Convention on the Law of the Sea (UNCLOS) dispute settlement provisions,' and a wide range of dispute resolution procedures contained in bilateral and

\footnotetext{
* Assistant Professor of Law, Boalt Hall School of Law, University of California at Berkeley. I owe thanks to Richard Brooks, Stephen Choi, Robert Cooter, Lori Fisler Damrosch, Aaron Edlin, Jesse Fried, Madeline Morris, Daniel Rubinfeld, Howard Shelanski, Beth Simmons, participants at the Columbia Law School Law and Economics Workshop, and an anonymous referee for helpful discussions and comments. Special thanks to Jeannie Sears and Nicholas James. Ryan Waterman and Jennie Wang provided outstanding research assistance. Financial assistance was provided by the John $\mathbf{M}$. Olin Foundation.

${ }^{1}$ The ICJ, WTO Dispute Settlement Understanding, and UNCLOS Tribunal represent the primary multilateral organs that adjudicate disputes subject to mandatory dispute resolution provisions.
} 
regional agreements including, for example, the North American Free Trade Agreement (NAFTA).

Despite the above efforts to establish international tribunals, it remains the case that when sovereign states enter into international agreements, they typically do not provide for the mandatory resolution of disputes. ${ }^{2}$ For example, the United Nations Charter lacks such provisions, as do most military agreements, environmental agreements, and many other international agreements. A survey of 100 treaties registered with the United Nations and published in the United Nations Treaty Series yielded 80 treaties without a mandatory dispute settlement mechanism and only 20 with such a mechanism. ${ }^{3}$

Although the reluctance of states to include mandatory dispute resolution clauses in their agreements is well known and, indeed, considered unremarkable among international law scholars, it should be puzzling for contract scholars. An international agreement is, after all, a contract that seeks to influence the behavior of states. If one assumes that states entering into international agreements hope for compliance and that dispute resolution provisions provide some increase in the penalty for the violation of an agreement, then one might expect the parties to adopt such provisions. ${ }^{4}$ Put another way, one might expect dispute resolution provisions to be common because they increase the credibility of a commitment by providing a compulsory mechanism through which alleged violations are investigated and the party at fault is publicly identified. Being identified as having violated international law is costly for a state because it leads to a loss of reputation in the eyes of both its counterparty and other states, and because it might give the offended state the right to impose sanctions of some kind. ${ }^{5}$ A loss of reputation harms a state because it makes it more difficult to enter into future agree-

\footnotetext{
${ }^{2}$ I am unaware of any comprehensive examination of the use of such clauses in treaties. A 1976 writing claimed that, of some 17,000 treaties registered with the League of Nations or United Nations, fewer than 4,000 contained any clause providing for the peaceful settlement of disputes. Among those with such a clause, a large percentage simply called for negotiation. Others required the ex post consent of all parties before the dispute was sent before an arbitral tribunal such as the ICJ. See Louis B. Sohn, Settlement of Disputes Relating to the Interpretation and Application of Treaties, 136 Recueil des Cours 205 (1976). See also Madeline Morris, High Crimes and Misconceptions: The ICC and Non-party States, 16 Law \& Contemp. Probs. 13,14 (2001) ("States are particularly unwilling to enter into broad commitments to adjudicate future disputes, the content and contours of which cannot be foreseen.").

${ }^{3}$ The survey reviewed treaties listed in the UN Treaty Series from May 1998 (the most recent UN Treaty Series available) and earlier, counting only those treaties that involved two or more states and were published in the series. Of the 20 treaties with a mandatory dispute resolution clause, 12 were bilateral investment treaties.

${ }^{4}$ The dispute resolution provisions considered in this paper are those with mandatory terms agreed upon prior to the development of a dispute. In addition, only terms that provide for the resolution of disputes by a disinterested third party are included. Thus, provisions for conciliation and negotiation are not included, nor are postdispute commitments to arbitrate.

${ }^{5}$ See Andrew T. Guzman, International Law: A Compliance Based Theory, 90 Cal. L. Rev. (forthcoming 2002), for a discussion of how reputation affects international law.
} 
ments. ${ }^{6}$ For example, the WTO dispute settlement mechanism is intended to increase the cost of violating one's trade obligations by calling for the end of violative measures and by identifying guilty states. ${ }^{7}$

The parties to a contract might resist increasing the sanction for breach if the existing sanction is already optimal. This is almost certainly not the case in the interstate context because the enforcement mechanisms available to states are weaker than would be the case under an optimal regime. ${ }^{8}$ If one accepts that the existing enforcement system among states is weaker than is optimal, and if dispute settlement provisions represent a way to increase the commitment level of states, one would expect states to adopt dispute settlement procedures in virtually all agreements. ${ }^{9}$ Yet states often avoid the use of dispute resolution clauses that offer a low-cost way of increasing the sanction for wrongdoing and the credibility of their promises.

The question of why states resist dispute settlement clauses, then, presents a puzzle. ${ }^{10}$ The existing literature offers some suggestions to explain this behavior, but, as shown in Section II, these explanations are incomplete and

${ }^{6}$ A state can unilaterally publicize a dispute without a dispute settlement provision, but uninvolved states may not be able to verify which party is at fault.

${ }^{7}$ Warren F. Schwartz \& Alan O. Sykes, The Economic Structure of Renegotiation and Dispute Resolution in the WTO/GATT System, $30 \mathrm{~J}$. Legal Stud. (forthcoming 2002) ("By serving as a vehicle for transmitting information about violations throughout the trading system, central dispute resolution enhances the reputational cost of cheating.").

${ }^{8}$ It is true that even in the absence of a dispute resolution mechanism, reputational mechanisms may reduce the incentive to violate an international commitment, but there is no reason to think that reputation is sufficient to allow contracting between states at the optimal level. This is so because reputational sanctions are limited in magnitude and can be unpredictable. Even a total loss of reputational capital may not be enough to deter a violation of international law. Reputational sanctions are also likely to underdeter breach because the actions of the parties may not be observable to third parties. In the absence of a disinterested adjudicator, the breached-against party cannot credibly demonstrate that the other party was at fault. See Guzman, supra note 5.

${ }^{9}$ In some unusual instances, one state may be better off if it cannot commit. For example, if commitment is possible, a state may have to choose between a commitment to assist an ally in the event of war and losing the goodwill of that ally. If commitment is not possible, the state can promise to provide military assistance and therefore maintain the friendship of its ally without committing itself to military support. In general, however, states are better off with the ability to make binding promises. Even in those circumstances in which a state is better off without the ability to commit, its would-be contract partner is worse off, and, taken together, the two are worse off in the absence of a commitment mechanism.

${ }^{10}$ One possible explanation for the absence of dispute resolution clauses in some international agreements is that they are designed to resolve coordination problems. Once established, treaties of this sort have no need for dispute resolution procedures because neither party has an incentive to cheat. The theory advanced in this paper explains the absence of dispute resolution agreements when states seek to overcome a Prisoner's Dilemma. Some scholars have suggested that all or virtually all treaties address coordination games. Jack L. Goldsmith \& Eric A. Posner, A Theory of Customary International Law, 66 U. Chi. L. Rev. 1113 (1999). If this is the case, of course, then dispute resolution clauses are unnecessary because nobody has an incentive to violate the agreement. That all agreements represent the resolution of a coordination game is not a commonly held view, however, and in any case, this paper is not the forum in which to address the question. 
difficult to reconcile with what we know about contracting, litigation, and settlement. ${ }^{11}$

This paper offers an explanation of why states include dispute resolution clauses in some agreements but not others. ${ }^{12}$ Key to the explanation is recognition of the fact that the sanction for the violation of an international agreement is reputational, and this reputational loss represents a net loss to the parties in the sense that one party suffers a loss while the other enjoys no offsetting gain. ${ }^{13}$ This is in contrast to the typical domestic case in which sanctions take the form of money damages. The use of a dispute resolution clause, therefore, increases the total costs of breach, which has two effects. First, it provides a benefit to the states because it increases compliance in much the same way as do money damages in the domestic context. Second, it imposes a cost on the states because it increases the joint cost of breach. Thus, for those cases in which a breach occurs despite the presence of a dispute resolution clause, the parties are worse off with a tribunal than they would be without one. ${ }^{14}$

The paper demonstrates that states are more likely to include dispute resolution clauses when the expected benefit from a future violation is small, when the marginal impact of the clause on compliance is large, and when the parties to the agreement face similar ex ante probabilities of breach. Dispute resolution clauses are also more likely in low-stakes than high-stakes agreements and in multilateral rather than bilateral ones. Normatively, the paper demonstrates that increasing the accuracy of tribunals will increase the use of dispute resolution clauses, even if the parties are risk neutral. It also offers support for the view that money damages (or other damages that take the form of transfers between the parties) should be encouraged.

As is the case with any positive theory of state behavior, the model presented in this paper makes assumptions about how states make decisions. First, it is assumed that states act rationally and in their own self-interest. Second, it is assumed that states act as unitary actors. Although not specif-

"This paper concerns only the ex ante commitment of states to use dispute settlement procedures. Whether states choose to submit themselves to some form of formal dispute settlement by a third party ex post is a different issue that is not addressed here.

${ }^{12}$ Other scholars have noted that dispute resolution clauses affect the willingness of states to enter into an agreement. See Joel P. Trachtman, The Theory of the Firm and the Theory of the International Economic Organization: Toward Comparative Institutional Analysis, 17 Nw. J. Int'l L. \& Bus. 470 (1996-97); James D. Fearon, Bargaining; Enforcement, and International Cooperation, 52 Int'1 Org. 269 (1998); Alan O. Sykes, Protectionism as a "Safeguard": A Positive Analysis of the GATT "Escape Clause" with Normative Speculations, 58 U. Chi. L. Rev. 255 (1991).

${ }^{13}$ The sanction may also take the form of retaliation through nonreputational means, for example, the imposition of trade restrictions. As discussed in Section IVE, the argument presented in the paper applies at least as well to sanctions of this sort as it does to reputational sanctions.

${ }^{14}$ Some readers may object that the parties could renegotiate before the tribunal renders a decision. This point is addressed in Section IVF. 
ically discussed, the model allows for the possibility that state preferences are the product of an interaction of domestic interests. What is really assumed, then, is that the domestic political process generates a policy that the state pursues. An alternative approach with which to analyze state decision making looks to domestic interest groups in an attempt to understand how domestic interactions lead to international behavior. ${ }^{15}$ This paper treats states as unitary actors because that assumption is sufficient for the present purposes and because it provides stronger predictive results. ${ }^{16}$

Section II of the paper outlines some of the existing explanations for state resistance to dispute resolution mechanisms and explains why they are incomplete. Section III presents the model itself, and Section IV explores possible extensions of the model, as well as its implications.

\section{Existing Explanations}

The reluctance of states to include binding dispute resolution clauses in their agreements has received limited attention from international law scholars. One reason for the lack of interest may be the fact that this behavior is so common as to be considered the norm-it is simply accepted that states rarely provide for dispute resolution. ${ }^{17}$ The existing literature offers several explanations for the behavior of states. Two of the most common are discussed below. In general, such explanations are neither satisfactorily developed in the literature nor the product of a theory of negotiation. ${ }^{18}$

\section{A. Maintenance of Control over Negotiations}

One of the most frequently advanced explanations for the absence of dispute resolution clauses in international agreements is that states prefer to retain control over disputes rather than turn to a third party. ${ }^{19}$ It is argued that resolution of a dispute through interstate bargaining and diplomacy is

${ }^{15}$ Warren F. Schwartz \& Alan O. Sykes, Toward a Positive Theory of the Most Favored Nation Obligation and Its Exceptions in the WTO/GATT System, 16 Int'l Rev. L. \& Econ. 27 (1996); Sykes, supra note 12; Anne-Marie Slaughter, Andrew S. Tulumello, \& Stepan Wood, International Law and International Relations Theory: A New Generation of Interdisciplinary Scholarship, 92 Am. J. Int'1 L. 367 (1998).

${ }^{16}$ See Guzman, supra note 5, for a discussion of the public choice assumptions and their use in international law scholarship.

${ }^{17}$ Not only do states rarely include dispute resolution procedures, but when they include some form of procedure, it is rarely mandatory. It is common, for example, for a "dispute resolution" clause to call for no more than conciliation and negotiation in the event of a dispute.

${ }^{18}$ I should add that existing discussions of dispute resolution often do not distinguish between ex ante commitments to dispute resolution and ex post agreement on its use. This paper considers only the ex ante aspect of the issue. The explanations discussed in this section may provide a better explanation for why states fail to enter into dispute resolution ex post than why they do not do so ex ante.

${ }^{19}$ See Morris, supra note 2, at 16; Arthur W. Rovine, The National Interest and the World Court, in 1 The Future of the International Court of Justice 462-73 (Leo Gross ed. 1976). 
more constructive than the use of third-party adjudication. ${ }^{20}$ Proponents of this theory claim that diplomacy is less likely than arbitration to harm the prestige of states and allows states to simply ignore or walk away from the dispute if nonresolution is the preferred outcome. In addition, a diplomatic solution does not create an international precedent in the same way that a published opinion does.

This argument misses the mark. There is no doubt that states value the opportunity to resolve disputes through diplomatic means, but the presence of mandatory dispute resolution does not prevent negotiation between the states involved in a dispute. Dispute settlement procedures are triggered only if one of the states prefers to abandon negotiation in favor of a formal process with a third-party adjudicator. Prior to the case's arrival before a tribunal, therefore, the parties have an opportunity to settle the case through diplomatic means. The domestic system of litigation and settlement offers an obvious analogy here. The court system stands ready to adjudicate disputes, but the vast majority are resolved through pretrial negotiation. Dispute resolution by the WTO represents an international example of negotiation in the presence of a mandatory dispute resolution process. Between 35 and 40 percent of all cases filed at the WTO are settled at the prepanel stage. ${ }^{21}$ The notion that a dispute settlement system prevents diplomatic bargaining is simply wrong. ${ }^{22}$

Assuming that states are both risk neutral and unable to predict which party will be at fault in the event of a dispute, there is no reason for them to avoid a dispute resolution clause ex ante. ${ }^{23}$ Although giving up control over the dispute will hurt a state in some cases, the ability to force its counterparty to submit to dispute resolution will help in others. Furthermore, one would expect a dispute resolution clause to increase the cost of breaching

\footnotetext{
20 "It is one thing to show that resort to the [International Court of Justice] is preferable to armed conflict; it is quite another matter to demonstrate that judicial processes are as valuable as ordinary out-of-court bargaining and discussion." Rovine, supra note 19, at 314. "[T]here is a more fundamental reluctance to submit to third-party adjudication that rests on the perceived advantages to States in some circumstances of retaining control over the resolution of disputes." Morris, supra note 2, at 17 (citing Rovine, supra note 19).

${ }^{21}$ Andrew T. Guzman \& Beth A. Simmons, To Settle or Empanel? A Transaction Cost Approach to the World Trade Organization's Dispute Settle Process, 31 J. Legal Stud. (forthcoming 2002). Marc Busch \& Eric Reinhart report that panels are established in only 43 percent of WTO cases. Marc L. Busch \& Eric Reinhardt, Bargaining in the Shadow of the Law: Early Settlement in the GATT/WTO Disputes, 24 Fordham Int'1 L. J. 158 (2000). This figure, however, includes all cases that have been filed and for which a panel has not yet been established. For many of those cases, there simply has not been enough time to determine whether there will ultimately be a panel. The Guzman and Simmons figure includes only cases that have been settled, gone to a panel, or been "inactive" for at least 3 years.

${ }^{22}$ Compulsory dispute resolution does, of course, affect the outcome of negotiations. In particular, it leads to a less favorable outcome for the breaching party.

${ }^{23}$ Risk neutrality is discussed in the next section.
} 
the agreement, thereby increasing compliance and the corresponding value of the agreement. ${ }^{24}$

\section{B. Risk of Losing}

Another oft-cited reason for the reluctance of states to enter into dispute resolution agreements is their fear of losing the case. ${ }^{25}$ To the extent that dispute resolution identifies the winners and losers in a dispute, a state benefits from a dispute resolution provision when it wins a case. The claim, therefore, is that states prefer to avoid the dispute altogether rather than risk losing - even if they also stand a chance of winning. In other words, states are risk averse. ${ }^{26}$

Risk aversion is an unsatisfactory reason for states to avoid dispute resolution for at least two reasons. First, recognizing that states enter into many international agreements and have frequent and repeated interactions with other states, it is hard to see why a state would be risk averse. Each individual commitment or compliance decision represents just a small fraction of the states' behavior. With many such interactions, one would expect states to seek to maximize the total value of their commitments rather than to avoid risk. In essence, states are well diversified in their international interactions, allowing them to reduce the overall risk to which they are exposed. ${ }^{27}$ Second, and perhaps more important, the use of a dispute resolution procedure may actually reduce the risk faced in any given agreement if one views the case from an ex ante perspective. Ex ante, a dispute resolution clause increases the likelihood of compliance, which can cause a reduction in the overall risk of the agreement.

\section{The Model}

Suppose that two countries, labeled A and B, seek to achieve cooperation through the use of a treaty. The timing of events is as follows. At $t=0$, the

\footnotetext{
${ }^{24}$ A related explanation for resistance to dispute resolution clauses is that states are unwilling to compromise their sovereignty. This is an unsatisfactory explanation for a number of reasons, including the fact that it does not distinguish cases in which dispute settlement is provided for from cases in which it is not. In any event, without a clear definition, simple appeals to sovereignty are too vague and malleable to have much explanatory value.

25 "Most obviously, but most fundamentally, states resist judicial settlement because they fear losing." Rovine, supra note 19, at 317.

26 "[T] willing a State will be to seek binding third-party adjudication." Morris, supra note 2, at 18. See J. G. Merills, International Dispute Settlement 293-94 (3d ed. 1998) ("when the result is all important, adjudication is unlikely to be used because it is simply too risky").

${ }^{27}$ It would be incorrect to respond that some disputes involve such a large potential loss that the existence of other agreements represents inadequate diversification. No individual dispute can impose losses on a state that exceed the cost of simply ignoring the dispute resolution clause. The damage that a state can suffer, therefore, is capped by the fact that there is no coercive enforcement mechanism in place.
} 
TABLE 1

Payoffs If There Are No Dispute Resolution Procedures

\begin{tabular}{lcc}
\hline & \multicolumn{2}{c}{ CountRY B } \\
\cline { 2 - 3 } Country A & Cooperate & Defect \\
\hline Cooperate & $(P, P)$ & $\left(-L, N_{\mathrm{B}}\right)$ \\
Defect & $\left(N_{\mathrm{A}},-L\right)$ & $(0,0)$ \\
\hline
\end{tabular}

states enter into a treaty. They can choose to include or omit a clause providing for the mandatory resolution of disputes. At $t=1$, each party learns the payoff it stands to receive if it complies with or violates the treaty. At $t=2$, the parties receive their payoffs.

At $t=0$, when the treaty is established, the parties know that the expected value of cooperation exceeds the expected value of noncooperation, but there is uncertainty regarding the payoff a party will receive if it breaches. If both countries comply with the terms of the treaty, they each receive a payoff of $P$, where $P>0$. A country that violates the treaty while the other country complies enjoys a positive payoff, $N_{i}, i=\mathrm{A}, \mathrm{B}$, where $N_{i}$ is a random variable whose distribution is known to country $i$, but not country $j$, where $j \neq i$.

The gain of $N_{i}$ can be thought of as an increase in a state's payoff as a result of an outside option that becomes available but that can be pursued only by breaching the treaty. The distribution of $N_{i}$ varies across states in part on the basis of the state's discount rate, which can vary across states and across time according to the interests of domestic institutions and players. If a country complies with the treaty while its partner breaches, the breachedagainst party suffers a loss of $L$. This loss might reflect, for example, the loss of investments made in reliance on the treaty. If both states violate the agreement, they both receive zero. ${ }^{28}$ The payoffs if there are no dispute resolution procedures are represented in Table $1 .^{29}$ Notice that under these assumptions, there will be compliance with the treaty in some states of the world, but the treaty itself provides no compliance pull-meaning that the

\footnotetext{
${ }^{28}$ This is a reasonable assumption because if both parties intend to breach, they can simply agree to abrogate the treaty-in which case, neither party will have violated its commitment. Even if there is a dispute resolution clause, the parties can agree to terminate the treaty if neither party wishes to comply.

${ }^{29}$ It is assumed that $2 P$ is larger than that expected value of $N_{i}-L$. If this is not the case, cooperation does not maximize the joint payoff. Note that the game should be thought of as the presented discounted value of a repeated game rather than a one-shot game. This is important because the game must be repeated for cooperation to emerge as a possibility in the absence of an enforcement mechanism.
} 
behavior of the parties is unchanged by the treaty. ${ }^{30}$

Compliance can be improved through the use of a dispute resolution clause. If the parties have included such a clause in the treaty, either party can call for the use of the dispute resolution procedures. For the moment, it is assumed that the arbitral body is able to identify the party responsible for a violation. ${ }^{31}$ This impartial determination of culpability imposes a cost on the breaching party in the form of a loss, $R$. This loss is modeled as a reputational loss that inhibits the state's ability to make credible commitments in the future. ${ }^{32}$ A reputational loss can emerge from a straightforward signaling model. ${ }^{33}$ Individual states have imperfect information regarding the willingness of other states to comply with their international obligations. When a state violates an obligation, that violation sends a negative signal to other states regarding its willingness to comply with its commitments. For now, the paper will proceed on the assumption that the loss is a reputational one. ${ }^{34}$ Section IVE demonstrates that the same results would hold for sanctions. It is assumed that a party refusing to appear before the tribunal, or otherwise disputing the authority of the tribunal, suffers the full reputational loss of $R$. One can think of this loss as the lost value owing to the reduced credibility of the country's future promises.

The dispute resolution clause also has another, positive, effect on the payoffs. Because states recognize that the presence of a dispute resolution clause at $t=1$ (when uncertainty is resolved and states make compliance decisions) generates a risk of a future reputational loss, the use of such a clause signals that the states involved expect to comply with the agreement. This generates a reputational gain for the signatory states, which we will call $\alpha$. The payoff $\alpha$ is received at $t=2$ along with the other payoffs to reflect the fact that the mere inclusion of the clause will have no effect if, for example, the agreement is amended to remove the clause before compliance decisions are made at $t=2$. For the same reason, if both states violate the agreement, the payoff to the states is assumed to be zero because neither state has an incentive to use the dispute resolution procedures to pursue the

\footnotetext{
${ }^{30}$ One could carry out the same analysis under an assumption that a failure to honor a treaty imposes some reputational harm even in the absence of a dispute resolution mechanism. As long as the dispute resolution procedures increase that reputational harm, one would get results analogous to those developed here.

${ }^{31}$ This assumption is relaxed in Section IVA.

${ }^{32}$ Guzman, supra note 5.

${ }^{33}$ See Andreu Mas-Collel, Michael D. Whinston, \& Jerry R. Green, Microeconomic Theory 450-60 (1995), for a presentation of this sort of model.

${ }^{34}$ By assuming that a reputational loss exists, I am assuming that international law can have at least some binding effect. I recognize that some are skeptical of this claim, but if international law has no effect, the mystery is not why states fail to establish dispute resolution procedures, but rather why they enter into international agreements at all. In any event, this debate continues in the international relations literature, and 1 put it to one side for present purposes. For a discussion of this debate, including my own views, see Guzman, supra note 5.
} 
TABLE 2

Payoffs in the Presence of Dispute Resolution Procedures

\begin{tabular}{lcc}
\hline \hline & \multicolumn{2}{c}{ Country B } \\
\cline { 2 - 3 } Country A & Cooperate & Defect \\
\hline Cooperate & $(P+\alpha, P+\alpha)$ & $\left(-L+\alpha, N_{\mathrm{B}}-R+\alpha\right)$ \\
Defect & $\left(N_{\mathrm{A}}-R+\alpha,-L+\alpha\right)$ & $(0,0)$ \\
\hline
\end{tabular}

case. It is assumed that $\alpha<R$, because if that is not so, the inclusion of a dispute resolution clause generates a positive reputational signal, even when the agreement is breached. If that were the case, every treaty would contain such a clause. The payoffs in the presence of dispute resolution procedures are represented in Table 2.

We denote the probability of compliance in the absence of a dispute resolution provision $\rho$. The term "compliance" is used here to describe the situation in which both parties honor the agreement. If the parties include a dispute resolution provision, breach becomes less attractive because a party that loses before a tribunal suffers the reputational loss of $R$. Let $q$ denote the marginal impact of a dispute settlement clause on the probability of compliance. ${ }^{35}$ Thus, in the presence of a dispute settlement clause, the probability of breach is $1-\rho-q$. Finally, assume that country A is responsible for any given breach with probability $\phi$ and country $B$ is at fault with probability $1-\phi$. These probabilities are known to the parties but unobservable to other states.

Consider first the case in which there is no dispute resolution procedure. The expected payoff to country A from the establishment of the treaty is given by ${ }^{36}$

$$
\rho P+(1-\rho)[\phi N-(1-\phi) L] .
$$

It is true that a state can publicize a breach unilaterally in an attempt to impose the reputational loss, $R$, on the breaching state. In this case, however, other states have no way of knowing which party is actually at fault, and each country will face a portion of the reputational loss. Rather than suffer this loss, the breached-against state will simply remain silent.

Now consider the payoff if the parties establish a dispute resolution procedure. Country A's payoff from an agreement with a dispute resolution clause is given by

$$
(\rho+q)(P+\alpha)+(1-\rho-q)[\phi(N-R+\alpha)-(1-\phi)(L-\alpha)] .
$$

\footnotetext{
${ }^{35}$ As discussed below, $q$ is a function of $R$.

${ }^{36}$ Without loss of generality, from this point on, the paper considers only the payoffs to country A. To simplify the notation, the subscript on $N_{\mathrm{A}}$ is dropped, and $N$ is used to indicate the expected value of $N_{\mathrm{A}}$.
} 
Comparing expression (2) and expression (1), a country prefers to include a dispute resolution clause if and only if

$$
\begin{aligned}
(\rho+q)(P+\alpha)+ & (1-\rho-q)[\phi(N-R+\alpha)-(1-\phi)(L-\alpha)] \\
> & \rho P+(1-\rho)[\phi N-(1-\phi) L] .
\end{aligned}
$$

Simplifying yields

$$
q P+\alpha>\phi[(1-\rho-q) R+q(N+L)]-q L .
$$

If the inequality in (3) is not satisfied, the parties prefer to establish the agreement without a dispute resolution clause.

Inequality (3) allows us to carry out some comparative statics to see how changes in various values are likely to affect the use of a dispute resolution clause. These comparative statics, however, must be done with care. Up to this point, $\alpha$ and $R$ have been modeled as constants. If the other values are allowed to change, however, these reputational variables may also change. Suppose, for example, that two states enter into a treaty with a dispute resolution mechanism. The reputational impact of compliance or violation will surely depend on the content of the agreement. If, for example, cooperation has no benefit $(P=0)$, it is hard to imagine that there could be a positive reputational impact $(\alpha>0)$ as a result of the inclusion of a dispute resolution agreement. ${ }^{37}$ Similarly, a state that breaches an agreement may not suffer a large reputational loss if the payoff from violation is so large relative to the payoff from cooperation as to make compliance unrealistic (that is, if $N-P$ is very large). For example, if a state fails to monitor and enforce emissions as required by an environmental treaty as a result of a war being fought on its own territory, it may not suffer any reputational harm because a violation in that context does not provide a meaningful signal to other states.

With the above in mind, consider how a change in $N$-the expected value of breaching one's obligation-affects the appeal of dispute resolution procedures. An increase in $N$ makes violation of the agreement more attractive at the margin because the benefits of breach are greater. ${ }^{38}$ This causes a reduction in the probability of compliance, $\rho$. A reduction in $\rho$ increases the cost of dispute resolution because it increases the probability of breach and, therefore, the probability that one of the parties will suffer a loss of $R$. An increase in $N$, therefore, reduces the likelihood that a dispute resolution clause will be included in the agreement.

\footnotetext{
${ }^{37}$ For example, an agreement between landlocked countries to refrain from entering into one another's territorial waters would presumably not carry reputational benefit, even if a dispute resolution clause were included.

${ }^{38}$ The value of $N$ may be larger because the state faces alternatives to compliance that yield large benefits or because the state discounts the future benefits of the agreement heavily, making the alternatives more attractive.
} 
At first glance, it appears that the range of values over which states prefer a dispute resolution clause increases for large values of $P$. This is what one would expect. If the gains from cooperation are large, there are greater benefits from a higher probability of compliance, which is one of the consequences of adopting a dispute settlement clause. A complete analysis, however, must consider the impact of a change in $P$ on the reputational variables, $\alpha$ and $R$. This paper avoids assuming a particular form for these variables because there is no satisfactory model of how reputation, as used here, interacts with the other variables in this presentation. It seems reasonable, however, to assume that the reputational sanction for breach, $R$, will increase as $P$ increases, all else equal. This is so because as $P$ gets larger, the benefits from a breach get smaller, and states that value the future benefits of the treaty will choose to comply. States with a high discount rate will breach for large values of $P$. As $P$ gets larger, one would also expect $\alpha$ to get smaller because large values of $P$ make breach less likely, making the inclusion of a dispute resolution clause-which imposes a cost only if there is a breach-a less meaningful signal. At the limit, if a dispute resolution clause were included in an agreement that no state would ever violate, then $\alpha=0 .{ }^{39}$ Strictly speaking, then, it is not possible to conclude that an increase in $P$ makes dispute resolution clauses more attractive without further assumptions about $\alpha$ and $R$.

It is straightforward to see that an increase in $\phi$, the probability that country A breaches, reduces the appeal of a dispute resolution clause. This reflects the fact that when country A breaches, it is better off if there is no dispute resolution clause. An increase in $\phi$, therefore, reduces the likelihood that country A will accept a dispute resolution clause. A reduction in $\phi$ reduces the appeal of such a clause for country A, but increases the appeal for country B. As $\phi$ deviates from $\frac{1}{2}$, one country likes dispute resolution more while the other likes it less. Recognizing that both parties must consent to such a clause, deviations of $\phi$ in either direction from $\frac{1}{2}$ reduce the likelihood that the clause will be adopted without some form of compensatory transfer from one state to the other. ${ }^{40}$ Where such transfers can be negotiated costlessly, the deviation has no impact on the likelihood of a clause. Where such transfers are costly to negotiate, however, the overall value of the agreement is reduced by the amount of the transaction costs incurred in arranging the transfer. In the international context, of course, such transfers can be costly to negotiate, and it is likely that, in some case, the transaction costs of negotiating a transfer will be large enough to prevent the inclusion of a dispute resolution clause.

\footnotetext{
${ }^{39}$ For example, inclusion of a dispute resolution mechanism in a treaty between Belize and Lesotho in which the states pledge to respect one another's borders would yield no reputation benefit.

${ }^{40}$ The value of $\phi$ might deviate from 12 if, for example, the distribution from which $N_{i}$ is drawn differs for countries $\mathbf{A}$ and $\mathbf{B}$.
} 
The magnitude of the reputational loss also affects the appeal of a dispute resolution clause. The impact of $R$ on the use of dispute resolution clauses, however, is uncertain in the model. On the one hand, an increase in $R$ reduces the appeal of such clauses because it increases the cost suffered by the breaching party. On the other hand, $q$ is a function of $R$ such that increased sanctions improve compliance, yielding a joint gain. From equation (3), it is clear that we cannot predict, a priori, how an increase in $R$ will affect the attractiveness of dispute resolution mechanisms. In order to make such a prediction, we would have to know the size of $\delta q / \delta R$, the marginal impact of a change in $R$ on $q$. If changes in $R$ lead to sufficiently large changes in $q$, dispute resolution clauses become more attractive as $R$ increases. It is also the case that the impact of a change in $R$ depends in part on $\phi$, the probability that country $\mathrm{A}$ is responsible for a breach. Specifically, changes in $R$ have a larger impact when $\phi$ is larger. This is so because country A suffers a reputational loss only when it is at fault.

That changes in $R$ have an ambiguous impact on the use of dispute resolution is important for the design of dispute resolution procedures. It shows that one cannot simply claim that states resist dispute resolution procedures because the cost of losing is too high. Under certain circumstances, an increase in the cost of losing a dispute settlement proceeding will increase the use of dispute settlement clauses. On the other hand, the claim that strengthening the international enforcement system will increase the use of these mechanisms is also overstated. In some cases, an increase in the reputational penalty for a violation of international law will reduce the use of dispute resolution clauses. ${ }^{41}$

Finally, the appeal of a dispute resolution clause is influenced by $q$, the marginal impact of such a clause on compliance. An increase in $q$ means that a dispute resolution clause generates a larger increase in the probability of compliance. This makes a dispute resolution clause more attractive. ${ }^{42}$

\section{EXTENSIONS AND IMPLICATIONS}

\section{A. Mistakes by the Tribunal}

This section explains how the potential for mistakes by a tribunal affects the behavior of states and the likelihood that a dispute resolution clause will be included in an international agreement. ${ }^{43} \mathrm{Up}$ to this point, it has been assumed that a tribunal is always able to identify the breaching party accurately. Therefore, when parties are deciding whether or not to adopt a

\footnotetext{
${ }^{41}$ The same can be said about an increase in other sanctions that do not take the form of transfers between the parties, as discussed in Section IVE.

${ }^{42}$ This can be seen most clearly in (3) by dividing both sides of the expression by $q$.

${ }^{43}$ For a discussion of the value of court accuracy in the domestic context, see Louis Kaplow, The Value of Accuracy in Adjudication: An Economic Analysis, 23 J. Legal Stud. 307 (1994).
} 
dispute resolution clause, their decision turns on the probability that they will violate the agreement but not on the court's ability to identify the breaching party. It is, of course, more realistic to assume that tribunals, like all courts, will sometimes make mistakes.

Assume that when a case is before a tribunal, there is a probability $\gamma$ that the court assigns blame to the wrong party. When the tribunal makes a mistake of this sort, a blameless state is labeled as the breaching party. Because the court's accuracy is common knowledge, states that lose before a tribunal suffer a less severe reputational loss than they would if tribunals never made mistakes. Third parties, recognizing that a losing state may nevertheless be innocent, will impose only a fraction of the full reputational sanction. Specifically, we assume that the sanction imposed will be a fraction, $1-\gamma$, of the full sanction, $R$. Similarly, the party that wins before the dispute resolution body suffers a reputational loss of $\gamma R$ because third parties realize that in a fraction $\gamma$ of cases, it is the winning party that has actually breached its obligation. ${ }^{44}$

The second effect of mistakes by the tribunal is to reduce the "compliance pull" of the dispute resolution process. For example, if the tribunal correctly identifies the culpable party only 75 percent of the time, there is a smaller incentive to comply than would be the case if the tribunal never made mistakes. Put differently, an increase in the frequency of mistakes reduces the magnitude of $q$, the marginal impact of dispute resolution, on the likelihood of compliance. This obviously reduces the payoffs to the parties of adopting a dispute resolution provision.

To identify the impact of tribunal error on the decision to adopt dispute resolution clauses, we calculate the expected payoff to country A at the time the agreement is reached: ${ }^{45}$

$$
\begin{aligned}
\rho P+q P-(1-\rho-q)[ & \phi(1-\gamma)(N-(1-\gamma) R) \\
& +(1-\phi)(\gamma)((1-\gamma)(-R)-L) \\
& +\phi \gamma(N-\gamma R)+(1-\phi)(1-\gamma)(-\gamma R-L)] .
\end{aligned}
$$

This expression can be restated as follows:

$$
\begin{aligned}
\rho P+q P_{\mathrm{A}}-(1-\rho-q)[ & \phi\left(N-R+2 \gamma R-2 \gamma^{2} R\right) \\
- & \left.(1-\phi)\left(2 \gamma R-2 \gamma^{2} R+L\right)\right] .
\end{aligned}
$$

\footnotetext{
${ }^{44}$ See page 318 infra for a discussion of why parties might bring cases even when they stand to suffer a loss by doing so.

${ }^{45}$ To simplify the notation somewhat, it is assumed here that $\alpha=0$. Because $\alpha$ is a constant, this assumption does not alter the analysis carried out below. The expression in square brackets accounts for country A's payoff when country A breaches the agreement and loses before the tribunal, when country B breaches and country A loses, when country A breaches and country $B$ loses, and when country B breaches and country B loses.
} 
Comparing this expression to (2), one can see that to determine the effect of the tribunal's mistakes on the country's payoff, we must determine whether the expression in square brackets is greater or less than $\phi(N-R)-(1-$ $\phi) L$. This turns out to depend on the magnitude of $\phi .^{46}$

Consider first the case in which $\phi=\frac{1}{2}$, meaning that each party is equally likely to violate the agreement. Under this assumption, expression (4) is easily simplified and is identical to expression (2). Thus, if the parties are equally likely to violate the agreement, the fact that the tribunal makes mistakes does not affect the payoffs in the event of breach. ${ }^{47}$

Now consider the case in which $\phi<\frac{1}{2}$. Under this assumption, expression (4) is smaller than expression (2). ${ }^{48}$ This means that country A receives a lower expected payoff from a dispute resolution clause when the tribunal makes mistakes than when the tribunal is perfect. When the probability that country $\mathrm{A}$ will be the state violating its obligation is less than one-half, therefore, mistakes by the tribunal reduce the value of dispute resolution to country A. This is so because, in expectation, mistakes by the tribunal impose costs on country A when country B violates its commitment and reduce the costs country $A$ faces when it breaches. If country $A$ is responsible for fewer than half the breaches, mistakes reduce its expected benefit from a dispute resolution clause. Since country A must consent to the inclusion of a dispute resolution clause, mistakes by the tribunal make it less likely that such a clause will be part of the agreement.

The remaining case is the one in which $\phi>\frac{1}{2}$. Under this assumption,

${ }^{46}$ If the tribunal is completely ineffective, meaning that $\gamma=12$, it must be the case that $q=0$ because the tribunal provides no compliance benefit. Substituting these values into (4) shows that expression (4) is then identical to expression (1), the payoff that exists in the absence of a mandatory dispute resolution mechanism. Thus, if dispute resolution is ineffective, there is no reason to adopt a mandatory dispute resolution clause. This raises an alternative explanation for the use of such clauses. If dispute resolution tribunals are often unable to identify the breaching party but are able to do so in other cases, this could explain why states adopt such provisions only occasionally. Even under this view, however, the theory advanced in this paper would still apply. Where dispute resolution is effective, it is will be adopted only when it increases the payoff to the parties. In addition, it is not certain that the parties to an agreement are able to anticipate the effectiveness of the tribunal at the time they decide whether or not to include a dispute resolution clause.

${ }^{47}$ This result contrasts with the claim that parties resist dispute resolution clauses because they are risk averse. See Section $\amalg B$.

${ }^{48}$ Let $X=2 \gamma R-2 \gamma^{2} R$. Because $\gamma<1$, we know that $X>0$. The contents in square brackets in expression (4) are

$$
\begin{aligned}
\phi(N-R & +2 \gamma R-2 \gamma 2 R)-(1-\phi)(2 \gamma R-2 \gamma 2 R+L) \\
& =\phi(N-R+X)-(1-\phi)(X+L) \\
& =\phi(N-R)+X(2 \phi-1)-(1-\phi) L .
\end{aligned}
$$

Since $\phi<12$, we know that $2 \phi-1<0$. Therefore,

$$
\phi(N-R)+X(2 \phi-1)-(1-\phi) L<\phi(N-R)-(1-\phi) L,
$$

meaning that (4) is less than (2). 
dispute resolution will have greater value for country A than is the case when the tribunal makes no mistakes. ${ }^{49}$ The impact on the likelihood of a dispute resolution clause, however, remains negative because country B will face a smaller payoff as a result of the mistakes, making country B less likely to agree to a dispute resolution clause. ${ }^{50}$

If $\phi \neq \frac{1}{2}$, then dispute resolution clauses are more likely if the tribunal can be expected to interpret the agreement and the facts consistently with the intent of the parties. The analysis, then, supports proposals aimed at improving the accuracy of tribunal decisions, including increasing the specialization of tribunals. For example, it may be worth considering changes in the composition of the WTO appellate body to reflect the subject matter of the case. ${ }^{51}$ An appeal relating to the Trade Related Aspects of Intellectual Property Rights Agreement would have a panel made up of individuals with expertise in intellectual property, while one relating to an antidumping case would be staffed by individuals with a background in international trade.

There remains the question of why a state would ever use the dispute resolution provisions when there is a chance that the tribunal will make a mistake. At least two reasons exist that could explain why a state would bring a case despite the fact that doing so might expose it to a loss. First, a state might bring a case to develop a reputation as a state that files suit against treaty violators. Second, in addition to the reputational impact of dispute resolution, the offended party may receive permission to impose economic sanctions, as is sometimes done in the WTO. Although these sanctions typically reduce the overall welfare of the sanctioning country, certain groups within the country will benefit. If these groups are politically powerful relative to those groups that stand to lose, they may be able to persuade the government to pursue the case. ${ }^{52}$

Notice that although this section considers mistakes by a tribunal, it applies equally well to tribunal decisions that go beyond the intent of the parties. Thus, a tribunal that interprets an agreement in such a way as to include requirements that the states did not intend makes a "mistake." This may explain why states are often unwilling to include dispute resolution clauses

${ }^{49}$ This ignores the impact of mistakes on $q$, the increased likelihood of compliance, which at least partially offsets the increased payoff to country A discussed in the text.

${ }^{50}$ Because the impact of mistakes is to shift the reputational loss between the parties, an assumption of zero transaction costs would eliminate the impact of mistakes on the appeal of dispute resolution. Any change in payoffs as a result of mistakes could be compensated for at the time the contract is signed. Even with such an assumption, however, there would remain a lower compliance incentive, which would reduce the incentive to include a dispute resolution clause.

${ }^{51}$ Currently, WTO panels are chosen with an eye to the subject matter of the dispute, but the appellate panel for a case is made up of three people drawn from a fairly permanent roster of seven.

${ }^{52}$ Schwartz and Sykes advance a similar argument regarding the use of unilateral sanctions within the trading system. Schwartz \& Sykes, supra note 15, at 23. 
in agreements that are open-ended and whose scope is uncertain. Even if the parties have agreed on the obligations imposed by the agreement, a tribunal may have a different understanding of the agreement. ${ }^{53}$ For example, the ICJ allows a state to confer jurisdiction upon the court for all disputes concerning international law between itself and any other state that has similarly consented to the court's jurisdiction. ${ }^{54}$ In practice, this "optional clause" has seen only limited use by states, despite the fact that it binds them only when both parties to the dispute have consented to jurisdiction. One possible explanation is the open-ended nature of the agreement. ${ }^{5 s}$

\section{B. The Multilateral Case}

To this point, the paper has focused on agreements between two countries, $A$ and $B$. The implicit assumption has been that there are many other countries in the world and that these countries interact with countries A and B. This assumption is necessary for the reputational loss suffered by a party as a result of its violation of international law to be a net loss for the parties to the transaction. Although it is true that a reputational loss is a loss for the affected party, it represents useful information for other states. When it is learned that a state has violated an international obligation, other states benefit from the knowledge. They may, for example, conclude that they should not enter into an agreement that previously had appeared worthwhile.

It is reasonable to ignore the value of this reputational information for many bilateral agreements because the information generated is a benefit to every country, so the breached-against party gets only a tiny fraction of the total benefit. When one considers a multilateral agreement that includes a large share of relevant states, however, the value of this reputational information must be taken into account.

Modeling the multilateral case is complicated by the fact that it is hard to know the relationship between the reputational loss felt by a breaching party and the informational gain enjoyed by other states. It seems reasonable to assume that the latter, when aggregated over all states, is at least as large as the former because the ultimate effect of dispute resolution is to provide information to all states. Given that the global community is receiving better information as a result of the dispute resolution clause, it follows that it is in a better position to distinguish welfare-increasing agreements from welfarereducing ones.

\footnotetext{
${ }^{53}$ Vagueness in the agreement may also represent a failure of the parties to agree on a more precise set of obligations, in which case they may avoid dispute resolution provisions because the probability of breach is higher.

${ }^{34}$ See Article 36(2) of the Statute of the International Court of Justice.

${ }^{55}$ Another possible explanation is that states gain very little from a blanket acceptance of the ICJ's jurisdiction. They are better off adopting dispute resolution clauses only in those agreements where doing so makes them better off.
} 
Despite the general assumption that informational gains are at least as large as reputational losses, it is hard to make general statements about overall welfare as long as one retains the assumption that transaction costs are substantial. The problem is that agreements require the consent of every participating state, and it may be that a tribunal's decision causes one state to conclude (accurately) that the agreement will generate losses for itself despite the fact that the agreement has a positive impact on worldwide welfare. Only agreements that represent a Pareto improvement are completed, even though many additional agreements may offer increases in worldwide welfare. In this environment, the use of a dispute resolution clause that leads to a reduction in a state's reputation may prevent individual states from entering into some agreements that would reduce their welfare, but no general statement can be made about the impact those deals would have on global welfare.

Although identifying agreements as bilateral and multilateral provides a useful proxy for the inclusion of the informational externalities generated by dispute resolution, it is more accurate to consider the degree of interaction among the parties to an agreement and between those states and third parties. For example, a bilateral agreement might generate relatively few informational externalities if the two countries interact more often and more closely with one another than either does with other states. On the other hand, a regional agreement with many states may fail to capture such externalities if all the states have frequent and important relationships with countries that are not party to that agreement.

What can ultimately be said about dispute resolution, therefore, is that agreements between states with a high degree of mutual dependence are more likely to have dispute resolution clauses. This is so because most of the informational benefit from a breach is captured by the breached-against party or other parties to the agreement. Put differently, the parties to the agreement behave in a fashion similar to parties in a closed system because they have relatively minor interactions with nonparty states. This may explain the use of dispute resolution clauses in some regional organizations such as NAFTA-regional interactions between the NAFTA countries represent a large percentage of the important relationships of the member states. ${ }^{56}$

\section{High-Stakes Issues}

International law scholars are in agreement that high-stakes cases are poor candidates for dispute resolution. The conventional reason is that "nations will not adjudicate matters which, they feel, they could not afford to lose or

${ }^{56}$ This is obviously less true for the United States than it is for Canada or Mexico. Nevertheless, Canada and Mexico combined represent a very large share of U.S. interactions with foreign states. For example, the two countries combined account for approximately one-third of U.S. trade. 
where, if they lost, they could not afford to obey the judgment." ${ }^{\text {57 }}$ The problem with this explanation is that the costs of losing before a tribunal are limited. With high-stakes issues, one would expect the losing party simply to ignore the judgment rather than compromise on an issue that is perceived to be of great national importance. ${ }^{58}$ The loss, then, would be limited to whatever direct sanctions are applied plus the loss of reputation. Even accepting that these sanctions may be significant, they seem inadequate to explain state aversion to dispute resolution in high-stakes agreements.

The theory advanced in this paper suggests that dispute resolution clauses are rare in high-stakes agreements because the inclusion of such a clause increases the loss to the parties in the event of a breach without significantly increasing the probability of compliance. Notice first that a state's compliance decision is unlikely to be influenced by reputational considerations when the stakes are high. This is so because the costs and benefits involved are sufficiently large in magnitude that the reputational loss as a result of a breach is unlikely to alter a state's compliance decision. In the context of a highstakes agreement, therefore, increasing the reputational cost of a violation through the use of a dispute resolution clause will generate only a small increase in the ex ante probability of compliance. In the language of the model, $q$ is small for high-stakes issues. As shown in expression (3) and the accompanying discussion, a small $q$ reduces the appeal of a dispute resolution clause.

\section{The Role of Damages and Injunctions}

The model presented in this paper assumes that sanctions in international law take the form of reputational sanctions. As long as these sanctions represent a net loss to the parties, there exists at least some incentive to avoid the use of dispute resolution provisions. If one could eliminate the loss to the parties as a result of the dispute resolution process and replace it with a transfer between the parties, dispute resolution clauses would be much more desirable.

Damages that take the form of transfers between the parties would reduce the role of reputational sanctions by supplementing the compliance benefit of a dispute resolution mechanism without providing a disincentive to use the mechanism. Even with money damages, of course, there may remain reputational sanctions that may deter the use of dispute resolution clauses.

In terms of the model presented above, the use of damages increases the probability of compliance, $q$, without affecting the joint loss in the event of

\footnotetext{
${ }^{57}$ Louis Henkin, How Nations Behave: Law and Foreign Policy 187 (2d ed. 1979). Morris, supra note 2, at 18 ("[T] the less willing the State is to submit the dispute for third-party adjudication.").

${ }^{58}$ See Guzman, supra note 5.
} 
a breach, $R^{59}$ Using money damages, then, will make it worthwhile to include a dispute resolution clause in agreements for which such clauses are not value increasing absent money damages. Money damages can also serve to increase the rate of compliance in agreements that include dispute resolution clauses-supplementing the reputational impact.

Money damages would also make it possible, at least in principle, to encourage efficient breach between states. By selecting the appropriate level of damages, states could be induced to breach if and only if it were efficient to do so. ${ }^{60}$

Though the obvious candidate for damages is money, the rarity with which states transfer money either as compensation for past acts or in order to obtain future benefits suggests that there are significant hurdles to the use of money as a form of damages. ${ }^{61}$ One exception to the general resistance to money damages appears to be those contexts in which a state interacts with private parties. In these situations, the use of money damages is sometimes acceptable to states. For example, bilateral investment treaties provide that a state that has expropriated the assets of a foreign firm must pay compensation. ${ }^{62}$ In at least these circumstances, therefore, money damages should be encouraged in order to increase the use of dispute resolution mechanisms. ${ }^{63}$ If the use of money damages as the exclusive remedy is problematic, using such damages as a supplement to other sanctions, including injunctions and reputational sanctions, would nevertheless be a step in the right direction. One can imagine, for instance, that violations of economic obligations, which typically cause financial damage to the injured party, could be at least partially remedied through the use of money damages. World Trade Organization panels, for instance, could call for the payment of money damages in cases involving economic injury. ${ }^{64}$

Another type of remedy that represents a transfer rather than a loss is the use of injunctions. This is a form of damages that is commonly used in international dispute resolution, including in the WTO. Where the violation

${ }^{59}$ See expression (3) above.

${ }^{60}$ The specified money damages would have to take into account the reputational harm resulting from the violation and subtract this from the amount to be paid from one state to the other.

${ }^{61}$ See Jagdish Bhagwati, After Seattle: Free Trade and the WTO, 77 Int'l Aff. 15 (2001).

${ }^{62}$ Andrew T. Guzman, Why LDCs Sign Treaties That Hurt Them: Explaining the Popularity of Bilateral Investment Treaties, 38 Va. J. Int'l L. 639 (1998); Kenneth J. Vandevelde, U.S. Bilateral Investment Treaties: The Second Wave, 14 Mich. J. Int'l L. 621 (1993).

${ }^{63}$ Consistent with the theory presented in this paper-including the claim that money damages make dispute resolution clauses more likely-of the 20 treaties surveyed for this paper that included a dispute resolution clause, 12 of them were bilateral investment treaties.

${ }^{64}$ This suggestion is not intended to minimize the significant problems that would accompany a decision to use money damages. One such problem is the measurement of the damages. A second is the fact that the international community does not generally have access to the use of coercive force to compel compliance with judgments. Thus, even if money damages were adopted, it may be impossible to compel the payment of the judgment in every case. 
is likely to be ongoing, the use of an injunction may increase the attraction of a dispute resolution mechanism, and one would expect dispute resolution clauses to be more common in such cases.

\section{E. Public Choice and Sanctions}

The previous section explains that financial payments would be a desirable form of damages because they represent transfers between the parties and thus do not provide a disincentive for the use of dispute resolution clauses. If money damages are unavailable, however, alternatives should be considered. One potential strategy, used by the WTO, permits the use of sanctions by the offended party to penalize the breaching party. Sanctions increase the cost of violating an agreement, but like a reputational loss, they almost always represent a net loss for the parties. The most typical form of sanction, for instance, is the imposition of trade restrictions-which lead to a welfare loss for all affected states, including the sanctioning party.

Despite the fact that the state imposing sanctions suffers a welfare loss, there are two reasons why it may nonetheless choose to proceed with such measures. First, a state may want a reputation for penalizing those that violate their agreements, and a failure to impose sanctions may harm that reputation. Second, there may be political reasons to impose sanctions. If, for example, the use of sanctions allows the government to satisfy the demands of a powerful local interest group, sanctions may be used even if they are welfare reducing for the state.

If there are political reasons for a government to use sanctions when it has the opportunity to do so legally, the impact of sanctions on the use of dispute resolution changes. If sanctions, despite their negative impact on domestic welfare, generate positive returns to decision makers, then they affect the use of dispute resolution clauses in much the same way as do transfers. That is, if sanctions represent a gain to the decision makers of one state and a loss to those of another, they do not reduce the appeal of a dispute resolution clause in the same way as a reputational loss. ${ }^{65}$ Thus, a dispute resolution process that permits the implementation of sanctions may lead to more frequent adoption of dispute resolution clauses than is the case when the only sanction is a reputational loss.

Even if dispute resolution clauses are adopted more often, however, the fact that they are adopted for political reasons means that their impact on welfare is uncertain. Using sanctions as a penalty may be desirable if the impact on compliance is sufficient to increase the expected payoff to the states despite the pure loss imposed in the event of a breach. On the other

\footnotetext{
${ }^{63}$ We assume here that the gains to the leaders of one state are equal in magnitude to the losses felt by the leaders of the other state. This need not be true, in which case we must assess whether there is a net gain or loss.
} 
hand, if the impact on compliance is small, giving states the ability to use sanctions reduces the expected benefit of a dispute resolution clause.

\section{F. Renegotiation}

This paper presents a model in which states sometimes choose not to include a dispute resolution clause in their agreements because when such clauses are triggered, a loss is imposed on one of the parties that does not represent a gain to the other party. In a world without transaction costs, however, a dispute resolution system that is costly would not lead to fewer dispute resolution clauses. Rather, it would lead to fewer appearances before tribunals. When faced with a dispute, the states involved would seek a negotiated solution in order to avoid the joint loss. In this context, the dispute settlement clause serves to alter the terms of the negotiated settlement because it changes the parties' threat points. In the absence of transaction costs, however, the parties would never actually proceed to litigation before the tribunal, so the loss would never be suffered. There would, therefore, be no reason for the parties to avoid dispute settlement clauses.

In the international arena, however, it is clear that transaction costs are substantial. One can imagine several reasons why states might find it difficult to make the sort of transfers that are necessary to avoid the use of dispute resolution. First, states are reluctant to engage in interstate cash transfers to resolve differences. This may be because the amounts needed to compensate an injured party are too large and states face fiscal constraints, or because it is costly, as a political matter, for policy makers to be seen as either buying the goodwill of a neighbor or selling the interests of their country.

Second, there may also be additional political constraints on efforts to settle disputes through negotiation. The voters of a state may perceive the settlement of a dispute to be a capitulation by their government, and this may be more costly to policy makers, in political terms, than a loss before a tribunal. When faced with a tribunal ruling, political leaders can change national policy and claim that they have no choice. They are, in other words, able to shift the blame for the policy change from themselves to the tribunal. In addition, if the subject of the dispute affects powerful lobby interests within one or both states, compromise may be difficult because a negotiated solution that harms any one of those interests may be politically unacceptable.

Finally, pursuing the case may have some value to the plaintiff because doing so may bolster its reputation as one that pursues dispute resolution when wronged. This need not violate the assumption that dispute resolution represents a joint loss because the breached-against state may be seen as weak and suffer a loss if it is learned that the agreement was violated and the state did not pursue it. That is, building a reputation for forcing breaching parties into the dispute resolution process may help a state to avoid a reputational loss of its own. 
The lesson from a consideration of renegotiation is that a reduction in transaction costs at the dispute stage is desirable. If these transaction costs can be reduced, states will be less likely to find themselves before a tribunal-even when a violation occurs-because negotiated solutions are more likely. This will increase the appeal of a dispute resolution clause in the original agreement and the likelihood of compliance. One example of current efforts to reduce transactions costs is the mandatory consultation period provided for within the WTO dispute settlement procedure. ${ }^{66}$

\section{Conclusion}

International legal scholarship, and indeed international law, is built on the premise that the international legal obligations of states alter the incentives of those states. One of the important research challenges facing the field is the development of an understanding of how commitments and behavior are related. This paper represents an attempt to further such understanding with respect to the use of dispute resolution procedures. International law scholars are familiar with the reluctance of states to include mandatory dispute settlement clauses in their agreements but have not, until now, developed a theory to explain this behavior. There is, on the other hand, a well-developed contract law literature that can be applied to the behavior of states. Though such an approach promises many benefits, the lack of a coercive enforcement structure in the international arena makes the analogy to contract imperfect and forces us to apply the lessons of contract law with caution.

The use of dispute resolution clauses is one of the areas in which analogy to contract is difficult. This paper has developed a theory of state behavior with respect to dispute resolution clauses that takes into account the unique features of the international arena. State reluctance to adopt mandatory dispute settlement clauses is explained by the fact that these clauses, when triggered, impose a joint loss upon the parties. States, therefore, will accept such a clause only if the benefits, in the form of increased compliance, outweigh the costs that must be borne in the event of breach.

The theory yields both positive and normative results. For example, it demonstrates that a dispute resolution clause is less likely, all else equal, if the expected value of a future violation is high. The theory also suggests that bilateral agreements are less likely to include dispute resolution provisions than are multilateral ones. More precisely, dispute resolution is more likely as the level of integration among the parties increases relative to the integration between the parties and other states. The level of integration matters because the more the informational externality generated by a dispute

\footnotetext{
${ }^{66}$ The complaining party cannot demand a panel until 60 days after a request for consultation. WTO, Dispute Settlement Understanding, art. 4(7). Whether the mere requirement of consultation reduces transaction costs is open to question, but the waiting period is intended to encourage settlement.
} 
resolution procedure is captured by the parties to an agreement, the more likely they are to include a dispute resolution provision. This offers a possible explanation of why some multilateral and regional agreements such as the WTO, the European Union, and NAFTA have dispute settlement procedures.

The paper also shows that dispute resolution clauses are most attractive if the parties are equally likely to violate their commitments. If one party has a higher probability of breaching its commitment, that party is less likely to accept a dispute resolution clause.

One of the normative lessons of the paper is that dispute resolution procedures should be structured to increase the likelihood that a tribunal will share the parties' understanding of an agreement. This is true even if the parties are risk neutral because mistakes by the tribunal make dispute resolution less appealing to at least one of the states. This provides one possible explanation for why states have rarely been willing to grant jurisdiction to international adjudicatory bodies whose roles go beyond the narrow interpretation of a treaty.

In addition, dispute resolution is more likely to be used if the sanction represents a transfer between the parties to a dispute. Recognizing the difficulty of establishing a regime with this form of damages, it is nonetheless worthwhile to try to increase the use of money damages or other transfers whenever possible.

The weakness of the international enforcement regime is a constant issue for international law scholars. This is so whether they are thinking about how to increase compliance with international commitments or defending their entire discipline from skeptics. One of the tools that promises to increase compliance is mandatory dispute resolution. If states can commit, ex ante, to resolving their disputes before an impartial tribunal, they increase the sanction associated with a violation-even if that sanction is only reputational-and therefore increase compliance. One of the shortcomings of mandatory dispute resolution has been the reluctance of states to include it in their agreements. The standard response of international lawyers-that states resist such clauses in order to keep their options open-is inconsistent with what we know about contracting, credibility, and commitment. This paper demonstrates that, coupled with a recognition of the fact that transaction costs are substantial in the context of an interstate dispute, it is possible to explain the behavior of states by focusing on the fact that mandatory dispute resolution imposes a net loss on the parties to an agreement. 